\title{
Avaliação do grau de maturidade dos processos de gestão de contratos de software e serviços de tecnologia da informação em empresas do Rio Grande do Sul
}

\author{
Reges Antonio Bronzatti \\ Faculdade Antonio Meneghetti (AMF) \\ Noemi Boer \\ Centro Universitário Franciscano (UNIFRA)
}

\begin{abstract}
Resumo: Dado o grande volume de contratos estabelecidos na área de tecnologia da informação (TI) em empresas brasileiras, a falta de mão de obra especializada para sua análise e a consequente ausência de processos claros de gestão e acompanhamento do seu ciclo de vida, o presente trabalho tem por objetivo avaliar o grau de maturidade dos processos de gestão de contratos de TI e suas vulnerabilidades decorrentes. A metodologia caracteriza-se como um estudo transversal, de natureza descritiva e de abordagem quantitativa e qualitativa. Participaram da pesquisa 46 organizações do Rio Grande do Sul, selecionadas entre as 200 maiores empresas do Estado. Para a coleta de dados foram utilizados questionários eletrônicos, com entrevistas complementares aos principais gestores de TI, realizadas pelo próprio pesquisador. Constataram-se situações de risco legal e econômico nas organizações pesquisadas em função do baixo nível de maturidade encontrado na gestão do ciclo de vida dos contratos de TI e erros de delegação nas empresas pesquisadas.
\end{abstract}

Palavras-chave: Gestão de contratos; BPM; gestão de processos; maturidade de processos; delegação.

\begin{abstract}
Given the large volume of contracts established in the area of information technology (IT) in Brazilian companies, the lack of skilled labor for their analysis and the consequent lack of clear processes for managing and monitoring the life cycle, this work has general objective to assess the degree of maturity of the management contract processes and their vulnerabilities arising. The methodology is characterized as a cross-sectional, descriptive and quantitative and qualitative approach. Participated in the survey, 46 organizations, from Rio Grande do Sul, selected among the 200 largest companies. For data collection were used electronic questionnaires, interviews with IT managers conducted by the researcher. There are cases of legal risk and economic, in the organizations surveyed due to the low level of maturity found in the life cycle management of contracts of IT and delegation errors in the researched companies.
\end{abstract}

Key-words: contract management; bpm; process management; process maturity; delegation.

BRONZATTI, Reges A.; BOER, Noemi. Avaliação do grau de maturidade dos processos de gestão de contratos de software e serviços de tecnologia da informação em empresas do Rio Grande do Sul. Revista Saber Humano, Recanto Maestro, n. 3, p. 145-158, 2013. 


\section{Introdução}

Em um mundo cada vez mais globalizado e competitivo, o grande volume de contratos estabelecidos nas áreas de tecnologia da informação nas empresas, a falta de mão de obra especializada para analisar e interpretar contratos técnicos complexos, a ausência de processos claros de gestão e acompanhamento do seu ciclo de vida com os fornecedores de softwares e/ou serviços de tecnologia da informação (TI) podem trazer perdas econômicas e consequências legais de enorme vulto aos contratantes.

Os negócios entre empresas, na aquisição de softwares e serviços de TI, atualmente, baseiam-se, em sua maioria, na existência de um contrato entre a parte que fornece e a que adquire. Por meio do contrato, duas ou mais organizações estabelecem o enquadramento da sua relação de vontades, independentemente de porte ou tecnologia que estiver sendo adquirida.

No entanto, apesar de o contrato ser a pedra que alicerça a construção das organizações, a maioria delas não conhece e perde o acompanhamento da sua execução. No Direito Romano, segundo Gomes (2008), a Lei das XII Tábuas enunciava que aquilo que a língua exprimisse se tornava um direito, ou seja, os sujeitos possuem liberdades contratuais, podendo escolher quando, com quem e de que forma contratar, além de estipularem, quando possível, as cláusulas contratuais. Concluído o contrato e observados os requisitos de validade, ficavam as partes vinculadas ao cumprimento da obrigação estabelecida, de forma que qualquer modificação na convenção celebrada teria de ser feita com a anuência de ambas as partes contratantes. Esse é um dos princípios basilares, até hoje, da teoria geral de contratos presentes no ordenamento jurídico brasileiro e conhecido como pacta sunt servanda (contrato é lei entre as partes).

Meneghetti (2004, p. 67) afirma que uma legislação é sempre "um perigo no interior da economia" e que pode colocar em risco a própria sobrevivência empresarial quando um líder se omite de administrá-la, uma vez que é um processo natural da globalização econômica. Reforça Meneghetti (2004, p. 121): "Não convém lutar contra as leis, mas observálas e usá-las". Líderes empresariais, atualmente, colocam um esforço grande na negociação de um contrato, muitas vezes, apenas com a visão da dimensão imediata financeira, esquecendo, no ato da delegação, a sua gestão e o controle posterior das cláusulas e tempos acordados, gerando sempre uma desvantagem própria. Acrescenta Meneghetti (2004, p. 154): "as leis, os computadores e o capitalismo contemporâneo propiciam a qualquer um discutir o mercado. Isso é uma grande ocasião para os mais inteligentes e uma progressiva derrota para os que não tem capacidade de jogar". Contratos ativos de uma organização são o melhor reflexo de qualquer negócio. São as consequências do que a organização decidiu comprar e vender.

Por serem tão importantes para a vitalidade das organizações, carecem, hoje, de mecanismos eficazes para o seu controle e acompanhamento de execução - atividades predominantemente delegadas aos principais gestores das empresas. Na área de TI, é comum líderes empresariais, simplesmente, a tratarem como uma "caixa-preta" e se omitirem de darem visão mais estratégica ao seu próprio business, gerando lacunas de conhecimento dentro da organização por escolherem pessoas de elevado conhecimento técnico para ocuparem a liderança dessas áreas, mas com pouquíssimo conhecimentos jurídicos ou de gestão empresarial, essenciais para a 
plena gestão de um processo adequado na contratação de softwares e serviços de TI. De acordo com a visão $\mathrm{FOIL}^{34}$, retratada em Meneghetti (2003), um líder empresarial tem a responsabilidade de delegar uma parte do seu próprio projeto a outros operadores que sejam uníssonos ao seu interesse e ao seu projeto. Nenhum de nós pode operar sem delegar a outros a realização de um projeto da empresa, simplesmente porque não se pode fazer ou saber tudo sozinho. O processo de delegar é uma das formas, raramente, previstas pelas "escolas de economia", sendo vasto e recheado de riscos quando executado por fiduciários legais inadequados, reafirma esse autor (objeto de ações delegadas por parte do empresário no que tange a questões técnicas específicas e inerentes à atividade da empresa).

Em resumo, afirma Meneghetti (2003, p.55), uma empresa é "um feixe de ações delegadas, uniconduzidas pelo empresário, que depois constituem um complexo de relações que efetuam o resultado desejado ou previsto". Uma escolha inadequada dese delegado poderá trazer consequências indesejadas para o próprio empresário.

Frente a essas observações, o presente estudo tem como objetivo geral analisar aspectos referentes ao processo de gerenciamento de contratos em empresas do Estado do Rio Grande do Sul, utilizando-se a aplicação de um modelo de gestão baseado em business process management (BPM). Especificamente, procurou-se analisar o nível de maturidade do processo de gestão de contratos de TI de 46 organizações, de diferentes portes, bem como identificar vulnerabilidades na gestão de contratos de TI, inerentes ao processo de delegação dos líderes empresariais, desde a fase de negociação

\footnotetext{
${ }^{34}$ FOIL (Formação Ontopsicológica

Interdisciplinar Liderística): realiza cursos de formação e eventos focados no melhoramento da eficiência de serviço do líder em qualquer campo operativo.
}

BRONZATTI, Reges A.; BOER, Noemi. Avaliação do grau de maturidade dos processos de gestão de contratos de software e serviços de tecnologia da informação em empresas do Rio Grande do Sul.

Revista Saber Humano, Recanto Maestro, n. 3, p. 145-158, 2013. até o seu encerramento. Considera-se que a utilização do modelo de gestão baseado no BPM permite aliar seus benefícios na gestão por processos, traz resultados financeiros concretos na redução de custos na aquisição de produtos e serviços de TI com o aumento da produtividade e, ainda, diminui os riscos legais inerentes à utilização de softwares baseados em direitos autorais de terceiros.

$\mathrm{O}$ artigo está estruturado em cinco seções, incluído esta introdução. O referencial teórico, segunda seção, discute o conceito de contrato, a gestão de processos, a Melhoria de Processo do Software Brasileiro (MPS-BR), o BPM e o ciclo de vida de um contrato. Na terceira seção, são descritos os aspectos metodológicos da pesquisa. A quarta seção apresenta dados referentes às empresas participantes, vulnerabilidades do processo e os resultados da análise das questões referentes ao grau de maturidade do processo de gestão de contratos encontrados nas organizações pesquisadas. As considerações finais encerram o estudo destacando que contratos de TI, nas organizações pesquisadas, são mal geridos e que a maioria delas estão expostas a riscos econômicos e legais.

\section{Fundamentação Teórica}

Criar um modelo de gestão de contratos, baseado em processos, que consiga otimizar e maximizar a aquisição de recursos tecnológicos é uma premissa fundamental para que as organizações alcancem altos níveis de produtividade e de redução de custos. Para explicitar este tema, esta seção está organizada em cinco tópicos. Inicialmente apresenta-se $\mathbf{o}$ conceito de contrato e sua importância histórica. Na sequência, apresenta-se a gestão de processos e como se contrapõe a departamentos, o MPS-BR como atual gestão estruturada por 
metodologia brasileira com foco na intenção de aumentar o nível de maturidade do processo de desenvolvimento de software, o BPM (business process management) como método inovador para alinhar a gestão de processos aplicada ao caso concreto e, por fim, o conceito de ciclo de vida de um contrato.

\section{$2.1 \mathrm{O}$ conceito de contrato}

Muitos são os conceitos de contrato, que partem essencialmente da descrição legal, repositório de todos os seus elementos objetivos e subjetivos. Trata-se, sem qualquer dúvida, de um dos mais importantes institutos jurídicos, porque é basilar de quase todas as relações humanas em sociedade e, principalmente, porque suporta as relações de negócio entre os contraentes.

Segundo Gomes (2008, p. 43), "Contrato é uma espécie de negócio jurídico que se distingue, na formação, por exigir a presença de pelo menos duas partes. Contrato é, portanto, negócio jurídico bilateral, ou plurilateral". Pereira (2009, p. 74) define contrato como "um acordo de vontades, na conformidade da lei, e com a finalidade de adquirir, resguardar, transferir, conservar ou modificar direitos". Sua estrutura ética é a vontade humana, a qual, por sua vez, se funda nos princípios de segurança e liberdade volitiva. O contrato reside na lei, como não poderia deixar de ser, ou na licitude de seu objeto, dado que o contrato, como suporte das relações jurídicas, repele as condutas ilícitas, visto que estas afrontam a ordem jurídica e social. O efeito de um contrato é o de criar obrigações entre as partes.

Do ponto de vista etimológico, o vocábulo contrato deriva do latim clássico, pois já era um instituto jurídico do Direito Romano: do latim contractus (contrato) e trahere (trazer, arrastar). $\mathrm{O}$ contrato é assinado por duas partes que foram atraídas, trazidas ou arrastadas para os mesmos objetivos. O contrato é um trato, do latim tractum, pedaço de couro, pano ou papel, em que dois se comprometem a fazer alguma coisa. Originalmente, cada um dos contratantes ficava com um dos pedaços em que era dividido. Desse modo, os sucessores poderiam provar que houvera um trato entre os falecidos. $\mathrm{O}$ contrato escrito surgiu da necessidade de registrar no tempo o enlace obrigacional, como título com força de exigir do obrigado a prestação assumida.

$\mathrm{O}$ ordenamento jurídico brasileiro, segundo a Lei 9.609/98, em seu artigo 9, é explícito em admitir o contrato como base para qualquer prova de legalidade de utilização de um direito autoral de software: "O uso de programa de computador no País será objeto de contrato de licença. $\mathrm{Na}$ hipótese de eventual inexistência do contrato referido no caput deste artigo, o documento fiscal relativo à aquisição ou licenciamento de cópia servirá para comprovação da regularidade do seu uso" (BRASIL, 1998).

De forma adicional, o artigo 12 da mesma lei estabelece a punição para quem desrespeitar os direitos contratuais do autor do programa de computador que estiver sendo utilizado dentro da corporação. É explícita, portanto, a necessidade de uma organização controlar, no Brasil, de forma inequívoca, todos os contratos de software utilizados dentro de uma empresa, inclusive com o arquivamento e a gestão dos documentos fiscais associados a esses contratos.

\subsection{Gestão de Processos}

De acordo com Gonçalves (2000), a ideia de processo não é nova na administração de empresas, mas o fato de se tornar o centro da gestão é realmente novo. De uma maneira geral, diversos modelos baseados em processos têm sido

BRONZATTI, Reges A.; BOER, Noemi. Avaliação do grau de maturidade dos processos de gestão de contratos de software e serviços de tecnologia da informação em empresas do Rio Grande do Sul. Revista Saber Humano, Recanto Maestro, n. 3, p. 145-158, 2013. 
estabelecidos e utilizados pelas organizações. É praticamente consenso entre os estudiosos de administração que somente empresas que conheçam e coordenem adequadamente seus processos essenciais (core process) serão capazes de sobreviver. Esses modelos de gestão por processos estão sendo aplicados em contraposição aos modelos de gestão estruturados por controle de eficiências operacionais departamentais.

As diferenças entre os modelos de gestão citados podem ser representados graficamente, como mostram as Figuras 1 e 2. No modelo de gestão por funções (Figura 1), tradicional, proposto por Probst (2002), são criadas "ilhas isoladas de conhecimento", uma vez que a barreira hierárquica e a barreira funcional limitam a capacidade de uma pessoa se comunicar com os outros departamentos, gerando ineficiência e baixa produtividade para a execução de tarefas, sejam simples ou complexas. $\mathrm{O}$ modelo de gestão de processos (Figura 2) difere em relação ao modelo funcional em pelo menos três pontos: são empregados objetivos externos (foco de e para o cliente); os colaboradores e recursos são agrupados para produzir um trabalho completo ponta a ponta; e a informação segue diretamente para onde é necessária, sem filtro da hierarquia, aumentando a eficiência e a eficácia organizacional.

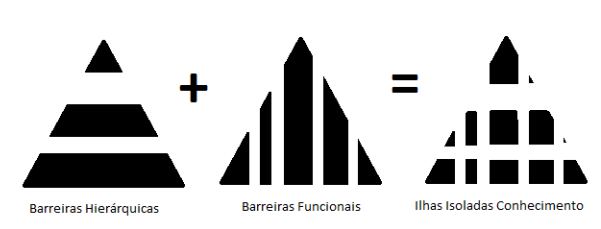

Figura 1: Modelo de gestão funcional. Fonte: Probst, 2002

Dentro desse conceito de obtenção de vantagem competitiva através da gestão por processos, pode-se destacar a metodologia do Business Process
Management (BPM), que é um núcleo desse trabalho.

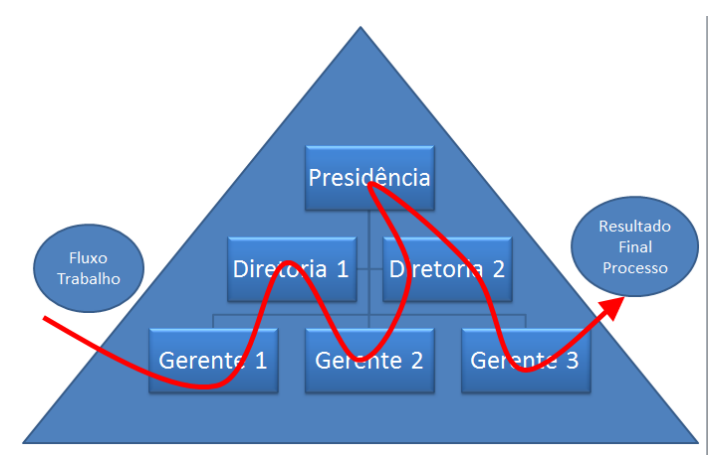

Figura 2: Modelo de gestão de processos. Fonte: Elaborado pelo próprio autor

2.3 MPS-BR (melhoria de processo do software brasileiro)

Uma das metodologias abordadas e possível para elevar o grau de maturidade de gestão dos softwares e serviços de TI contratados, no Brasil, é o MPS-BR (Melhoria de Processo do Software Brasileiro). Esse programa está em desenvolvimento desde dezembro de 2003 e é coordenado pela Associação para Promoção da Excelência do Software Brasileiro (SOFTEX), contando com apoio do Ministério da Ciência e Tecnologia (MCT), Financiadora de Estudos e Projetos (FINEP) e Banco Interamericano de Desenvolvimento (BID). O MPS.BR baseia-se nos conceitos de maturidade e capacidade de processo para a avaliação e melhoria da qualidade e produtividade de produtos de software e serviços correlatos (S\&S/C) (SOFTEX, 2009).

O MPS.BR está descrito através de documentos em formato de três guias: Guia Geral, contém a descrição geral do MPS.BR; Guia de Aquisição, que descreve o processo de aquisição de software e serviços de TI, e Guia de Avaliação, que descreve o processo e o método de avaliação MA-MPS, os requisitos para avaliadores líder, 
avaliadores adjuntos e Instituições Avaliadoras.

O Guia de Aquisição do MPS-BR descreve um processo de aquisição de software e serviços relacionados a desenvolvimento, implantação, operação e evolução do software. Ele está baseado nos processos de aquisição da norma ISO/IEC 12207 (Software Life Cycle Process - Processo de Desenvolvimento de Software) e complementado pela norma IEEE STD 1062:1998 (Recommended Practice for Software Acquisition - Práticas Recomendadas para Aquisição de Software). Segundo o MPS$\mathrm{BR}$, em seu guia de aquisição, o processo de aquisição de software e serviços de TI é composto de 4(quatro) etapas: preparação da aquisição, seleção do fornecedor, monitoração do fornecedor e aceitação pelo cliente. A gestão do ciclo de vida de um contrato de TI, segundo o guia de aquisição do MPS-BR, deve seguir um processo, com pelo menos essas quatro etapas, dentro de qualquer organização. Esse trabalho foca apenas nas recomendações desse Guia de Aquisição do MPS-BR.

\section{$2.4 \quad$ O BPM (Business Process Management)}

Uma das formas de implementação de um processo de gestão de contratos de TI, de modo prático e funcional, como descrito acima pelo MPS-BR, é a utilização de uma notação simplificada que descreve processos de uma forma simples e intuitiva no que tange ao gerenciamento de processos de negócio, como, por exemplo, o BPM, em que se entende que o estudo de um processo inicia pela sua modelagem, análise e desenho, até chegar às etapas de gerenciamento e à sua transformação ou automação.

Um processo é um conjunto de atividades realizadas inter-relacionadas ou interativas que transformam insumos (entradas) em produtos (saídas), afirma Baldam (2010). Gonçalves (2000) reforça que um processo é um conjunto de atividades que toma uma entrada, adiciona valor a ela e fornece uma saída a um cliente específico. Ambos os autores reforçam que os processos são importantes, pois é através deles que as empresas exercem suas funções, onde todo trabalho realizado faz parte de algum processo de negócio.

Para visualizar e identificar processos das empresas, é preciso uma análise que verifique quais os processos essenciais (relacionado ao foco da empresa) e quais os processos auxiliares, verificando como a empresa realiza sua função desde o primeiro contato com $o$ cliente até a entrega e avaliação do produto/serviço.

O BPM ajuda empresas a identificarem a importância estratégica de seus processos e a tirarem vantagens competitivas disso. Serve também para proporcionar ao gestor uma maior facilidade de encontrar oportunidades de melhoria para o serviço prestado ao cliente por meio de indicadores de resultados. O BPM controla processos por meio de uma série de índices de avaliação por processos, como, por exemplo: pode ser avaliado o tempo de execução dos processos, melhorias, desempenhos e acompanhamento do processo corrente. Esses índices devem ser voltados às necessidades da empresa, referentes aos seus processos especificamente. O BPM pode gerar melhorias em termos de rapidez em que o processo é realizado, eficácia, qualidade e custo.

O BPM pode ser utilizado em uma grande variedade de setores. Por exemplo, no setor de varejo, no setor industrial, no setor educacional, no setor governamental, etc. Pode também ser utilizado em diversos departamentos das empresas, como, por exemplo, no departamento financeiro, recursos humanos, tecnologia entre outros. A metodologia do BPM 
permite que, através de uma execução e de um controle mais eficaz, processos possam ser melhorados em cada uma dessas áreas e integrados com outras unidades internas ou até mesmo com clientes externos.

Segundo o CBOK (2009), o gerenciamento de processos de negócio é uma abordagem disciplinada para identificar, desenhar, executar, documentar, medir, monitorar, controlar e melhorar processos de negócio automatizados ou não, para alcançar os resultados pretendidos consistentes e alinhados com as metas estratégicas de uma organização.

Rosemann (2006) comenta que gráficos de fluxos e mapeamento de processos parecem existir desde que o homem dominou a escrita de símbolos. Uma das primeiras utilizações sistemáticas de diagramas de fluxos foi desenvolvida por Goldstine e Von Neumann em 1946, como parte de metodologia de desenvolvimento de software. Segundo Baldam (2010), existe uma quantidade significativa de metodologias para representação dos processo de negócios, ou mesmo para simplesmente elaborar fluxogramas, mas uma destaca-se pela sua simplicidade e objetividade: a BPMN (BPM Notation).

A especificação BPMN, criada pelo BPMI (BPM Initiative), em 2006, provê uma notação gráfica para representar processos de negócios em um diagrama. $\mathrm{O}$ objetivo do BPMN é servir de apoio ao uso do BPM por não especialistas, fornecendo-lhes uma notação bastante intuitiva que, no entanto, permite representar processos de negócios complexos.

Segundo Baldam (2010), a especificação BPMN oferece ainda uma conexão entre a representação gráfica e a construção de linguagem de execução de processos BPEL4WS. Utilizando-se a BPMN, é possível mapear e automatizar o processo do MPS-BR, de forma a garantir o completo ciclo de vida e controle de um contrato de software e/ou serviço de TI, já que as etapas propostas pela metodologia do MPS-BR se aplicam a ambos, independentemente do escopo formal do próprio contrato, conforme visualizado na Figura 3.

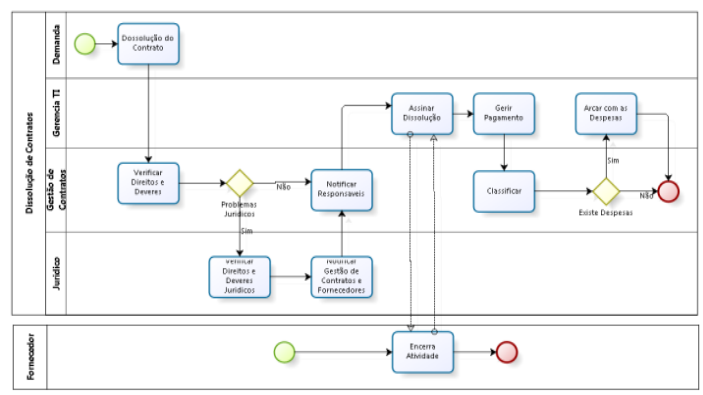

Figura 3: Exemplo de uma etapa do processo de gestão de contratos de TI em notação BPMN.

Fonte: Elaborado pelo autor deste estudo.

\section{$2.5 \mathrm{O}$ ciclo de vida de um contrato}

Gerenciar um grande volume de contratos é uma tarefa que demanda dos gestores muito tempo e dedicação, devido à enorme quantidade de cláusulas contratuais, prazos de renovação, entre outros fatores a serem controlados. Esse processo de gestão do ciclo inicia muito antes da sua formalização, quando uma parte define a necessidade de estabelecer uma relação comercial e termina geralmente após a vigência do contrato, quando realmente prescrevem todas as obrigações relacionadas.

Para atender a necessidade de um gerenciamento eficaz de contratos, hoje, no mercado, existe um modelo de trabalho, originado nos EUA, chamado CLM (Contract Lifecycle Management) ou Gestão do Ciclo de Vida dos Contratos. O CLM visa padronizar e facilitar a gestão dos contratos desde a criação até o seu encerramento. Segundo Freitas (2009), a metodologia que trata desse ciclo de vida de contratos envolve um modelo de processos, atribuições e ferramentas adequadas à gestão. A referência às melhores práticas em nível mundial na

BRONZATTI, Reges A.; BOER, Noemi. Avaliação do grau de maturidade dos processos de gestão de contratos de software e serviços de tecnologia da informação em empresas do Rio Grande do Sul. Revista Saber Humano, Recanto Maestro, n. 3, p. 145-158, 2013. 
gestão de contratos está baseada no CMBOK (Contract Management Body of Knowledge).

Nesta linha, similar, de metodologia para gestão de contratos, surge, no Brasil o método GCVC (Gestão do Ciclo de Vida dos Contratos). Catalogado na Biblioteca Nacional do Rio de Janeiro desde 2008, em site de livre acesso e em cursos (http://www.contratos.net.br/), adotado gratuitamente por empresas de diversos ramos de atividade, dos segmentos público e privado, esse método é a visão de controlar o contrato desde a especificação do objeto a ser contratado (antes do contrato existir) até o final das obrigações (que geralmente ocorre após o final da vigência contratual). Comparando-se os métodos GCVC e MPS-BR, concluiu-se que ambos estão alinhados no que tange ao controle do ciclo de vida dos contratos, mas o MPSBR aborda de forma mais especializada e ampla o processo de gestão de softwares e serviços de TI.

\section{Metodologia}

Esta pesquisa caracterizou-se como um estudo transversal, de natureza descritiva e de abordagem quantitativa e qualitativa, organizada em duas etapas. A primeira etapa compreendeu a elaboração do referencial teórico sobre o tema, e a segunda, um estudo exploratório baseado em um questionário composto por 30 (trinta) perguntas sobre o estágio atual do processo de gestão de contratos de software e serviços de TI aplicado a diversas empresas, de diferentes segmentos econômicos, acrescida de algumas entrevistas pontuais, com roteiro estruturado, aos principais gestores de TI dessas organizações.

A pesquisa visou avaliar o estágio de maturidade do processo existente na gestão do ciclo de vida de contratos de software e serviços de TI. O universo de empresas, alvo da análise, foi concentrada nas 200 maiores empresas do Rio Grande do Sul, tendo como fonte a matéria e pesquisa da Revista AMANHÃ, publicada em Porto Alegre-RS, na edição de agosto de 2010.

Os respondentes da pesquisa foram 46 gestores principais da área de TI dessas organizações. As respostas de 40 empresas participantes foram obtidas por meio eletrônico e 6 por meio de entrevistas pessoais.

O instrumento principal de coleta de dados (questionário) foi particionado em três grupos: dados de identificação do principal gestor da área; dados de identificação da organização associada e dados de execução do processo de gestão de contratos. Todos os entrevistados tiveram suas identidades e informações mantidas em total sigilo. A abordagem do questionário seguiu a escala de Likert, que permitiu identificar o grau de maturidade da organização quanto ao seu processo atual e que os permitiu classificar, segundo Parker (1995), em seis níveis de maturidade: processo inexistente, processos repetitivos, processos definidos, processos gerenciados, processos otimizados e processos integrados.

$\mathrm{O}$ projeto de pesquisa foi aprovado pelo Comitê de Ética - CEP SH/AMF, com o número de registro 2011.04/32 em 01 de abril de 2011, e os participantes assinaram Termo de Consentimento Livre e Esclarecido, conforme prevê a Resolução 196/96 do Conselho Nacional da Saúde.

\section{Resultados e Discussão}

Para melhor compreensão do estudo, na primeira parte desta seção são apresentados dados referentes às empresas participantes e aos respondentes. $\mathrm{Na}$ segunda parte, são descritos os resultados e a análise das questões referentes ao grau de maturidade do processo de gestão de 
contratos encontrados em suas organizações.

4.1 Caracterização das empresas participantes e dos respondentes

As organizações participantes da pesquisa eram $89 \%$ do setor privado e $11 \%$ do setor público. O segmento que mais se destacou nas respostas foi a área industrial com 52\%, seguido pelo segmento de educação com $11 \%$, serviços financeiros com $7 \%$, tecnologia com $4 \%$ e energia com $1 \%$.

Com um índice expressivo de $91 \%$, todos os sujeitos da pesquisa pertenciam a empresas com mais de 25 anos de mercado; $54 \%$ eram organizações com mais de 50 anos de atividades no Estado do Rio Grande do Sul.

Os respondentes são, na sua grande maioria, do sexo masculino (89\%), com idade entre 31 e 50 anos (74\%), casados (76\%). Possuem ensino de graduação ou pós-graduação $(81 \%)$, com formação na área de tecnologia $(63 \%)$ ou administração (22\%) e estão atuando dentro da mesma organização em um período superior a 10 anos (80\%), exercendo cargos de Gerente ou de Diretor de Tecnologia (83\%).

As organizações pesquisadas possuem um orçamento anual para contratação de soluções e serviços de TI acima de 1 milhão de reais (63\%); $24 \%$ possuem orçamento superior a 5 milhões de reais. As organizações com mais de 1000 colaboradores representaram 56\% do universo de participantes da pesquisa; $15 \%$ possuem mais de 5000 colaboradores. O número médio de fornecedores, típico dessas empresas, fica entre 11 e 25 fornecedores de TI (54\%), tendo um número médio de contratos ativos de TI entre 10 e 50 (80\%). São poucas as organizações que ultrapassam um número acima de 100 contratos ativos $(9 \%)$.
4.2 Avaliação e análise do grau de maturidade do processo gestão do ciclo de vida dos contratos

A pesquisa, pelo conjunto de respostas obtido, revelou situações de grande risco legal e econômico nas empresas do RS no que tange à gestão do ciclo de vida dos contratos de soluções e serviços de TI.

Foram identificadas inúmeras vulnerabilidades nas organizações pesquisadas no que tange à integração entre os diversos atores funcionais do processo de gestão dos contratos, ausência de controles mínimos desde o momento da aquisição de um produto ou serviço de TI até o seu encerramento, com o distrato formal da relação estabelecida.

Um resumo dos principais pontos de vulnerabilidade encontrados nas empresas pesquisadas, conforme relação com as etapas básicas do processo de aquisição de software e serviços sugerido no guia de aquisição, do MPS-BR, são apresentados no Quadro 1.

Os possíveis efeitos, apontados no Quadro 1, comprovam um baixo nível de maturidade do processo de gestão de contratos de TI presentes nas organizações pesquisadas. São fatores geradores de custos que provocam perdas financeiras concretas nos mais diversos modos $\mathrm{e}$ expõem a riscos legais, por exemplo, na falta de controle de contratos de software, motivo pela qual os custos podem chegar até 3.000 vezes o valor de um único software utilizado de forma ilegal, colocando em risco a própria existência da organização e prejudicando a própria organização, pois pode passar a ser considerada como uma empresa, "pirata de software", gerando danos incalculáveis a sua própria imagem ( ORRICO, 2004).

O simples fato de que $96 \%$ das organizações admitem que não conseguem cumprir prazos com áreas de negócios solicitantes de serviços ou soluções de TI já demonstra a falta total de controle das 
organizações em planejar de forma clara os indicadores da primeira etapa do processo de gestão de contratos, que é, segundo o MPS-BR, a fase de aquisição e negociação, na qual, supostamente, os esforços são e devem ser sempre maiores (SOFTEX, 2009). Modelos de maturidade de um processo organizacional definem o nível de consciência para as melhores práticas de gerenciamento operacional e otimização das atividades integradas de uma organização, segundo $\mathrm{o} \quad \mathrm{CBOK}$ (2009).

Um modelo de maturidade prevê uma forma de identificação de qual estágio a organização se encontra, em relação à aplicação ou utilização do modelo, permitindo tomar algumas ações: priorizar ações de forma que a evolução seja mais efetiva; avaliar se as ações estão surtindo efeito, trazendo a evolução esperada e aumentar a previsibilidade dos resultados obtidos pela organização.

Os dados apresentados no permitem inferir que as organizações pesquisadas ainda se concentram em um estágio de maturidade baseada nos níveis mais básicos da escala, com um grau de controle e monitoração do ciclo de vida dos contratos de TI muito baixos, reforçando o risco legal e econômico a que as organizações estão expostas. No nível zero de maturidade de processos estão $20 \%$ das organizações onde as atividades básicas são geralmente executadas, mas falta rigor no planejamento e na execução. $\mathrm{O}$ desempenho das atividades pode ser confuso, imprevisível e inconsistente e resulta em entregas de serviços de baixa qualidade, incertezas quanto aos prazos de entrega e estouro dos orçamentos de custos. O desempenho nesse nível depende de habilidades e dedicação individuais.

Em $25 \%$ das organizações pesquisadas no nível 1 , a execução de um processo de gestão de contratos já é planejada e a execução das principais atividades é gerenciada e caminha progressivamente para processos bem estruturados, mas ainda com alto grau de atividades sendo controladas de forma manual. Uma grande parte das organizações entrevistadas encontra-se no nível 2 (31\%), no qual as atividades básicas são desempenhadas segundo um processo bem definido, seguindo padrões adotados por toda a organização. Há um início do uso de medições para ajudar no gerenciamento de processos.

A partir do nível 3, a organização está focada no gerenciamento de processos, mas, segundo a pesquisa feita, apenas $11 \%$ das organizações se encontram nesse estágio. Nesse nível, medições de desempenho detalhadas são coletadas e analisadas e tem-se conhecimento da capacidade do processo e boa margem de acerto nas previsões de desempenho. No nível 4, as metas de desempenho baseadas nos objetivos do negócio são quantitativamente estabelecidas e são realizadas medições sistemáticas para fornecer feedback sobre o desempenho do processo e orientar as ações de melhoria e inovação ao próprio processo em si. Apenas $8 \%$ das empresas pesquisadas encontram-se nesse estágio.

No nível 5 encontrou-se o menor número de organizações, pois apenas 5\% das organizações pesquisadas consegue integrar processos organizacionais com o ferramental tecnológico já existente na empresa e garantir automação completa sobre controle orçamentário e controle de aprovações de um setor para outro.

Então, por que uma organização, sendo consumidora de softwares e serviços de TI, em alguns casos, de elevados valores, preocupa-se com a realização de todas as atividades da negociação visando diminuir custos e, muitas vezes, ainda ignora completamente ou trata de forma superficial $o$ acompanhamento posterior à sua aquisição e que define a relação formal com os seus fornecedores? 
Algumas respostas sobre isso foram identificadas na pesquisa. Por exemplo, $65 \%$ das organizações afirmam que, uma vez estabelecido, não se tem mais acesso ao próprio contrato, que fica arquivado em local de difícil acesso. Além disso, 91\% dos entrevistados admitem desconhecer metodologia de BPM ou o que seja realmente um processo de gestão de contratos de TI.

Como um reforço a essa constatação, há o baixo nível de maturidade de gestão desse processo, uma vez que $85 \%$ dos entrevistados admitem não fazer ou não aplicarem nenhum método de melhoria do processo de gestão do ciclo de vida do contrato. Além disso, o risco legal das empresas no que tange ao controle de direitos autorais, por exemplo, de softwares é muito alta, já que $91 \%$ das organizações admitem não possuírem controles de aquisições de softwares dos últimos dez anos, gerando um passivo e um descontrole desses contratos.

\section{Considerações Finais}

O trabalho teve por objetivo geral analisar aspectos referentes ao processo de gerenciamento de contratos em empresas do Estado do Rio Grande do Sul, utilizando-se de um modelo de gestão baseado em business process management (BPM). A análise da literatura sobre o tema e dos dados obtidos por meio da pesquisa permitiram a elaboração das considerações descritas a seguir.

- A implementação de um contrato de software ou serviço de TI sem o prévio estabelecimento dos seus mecanismos de controle posterior levará, muitas vezes, a uma execução que não atingirá os objetivos desejados, ou que será totalmente falha com os interesses preliminares das partes.

- Não havendo controle do ciclo de vida contratual dentro de uma organização, os resultados previsíveis significarão prováveis desgastes entre as partes, exposição a riscos legais e custos econômicos.

- A competência e o empenho com que os executivos de uma organização escrevem e negociam contratos são grandes determinantes da saúde financeira da empresa. A forma como se efetua o acompanhamento da execução dos contratos (as partes envolvidas e as suas responsabilidades, as ações que são necessárias executar, as renovações e extensões que são necessárias negociar e controlar) é ainda mais importante. No entanto, o melhor contrato negociado e escrito pode ser completamente inútil se não for gerido de forma adequada após sua formalização.

- A própria armazenagem dos contratos (impressos ou digitalizados) é um fator crítico para o sucesso no controle do ciclo de vida de um contrato. Muitas vezes, uma organização perde o rastro dos seus contratos, porque simplesmente o executivo que originalmente preparou e negociou o contrato já não se encontra na mesma posição na organização, ou porque foi elevado a uma posição superior ou diferente, ou porque aceitou um novo desafio em outra companhia.

Esse descontrole do arquivamento de contratos, por si só, tem como resultado a perda de "consciência" sobre determinados negócios realizados. Dessa forma, perde-se um substancial e precioso conhecimento sobre a própria identidade da organização.

Atualmente, os contratos de TI, nas organizações pesquisadas, são mal geridos. Conforme comprovado neste trabalho, a maioria delas estão expostas a riscos econômicos e legais conforme detalhado no Quadro 1. Existem vários fatores que podem contribuir para essa situação, mas que têm origem no processo de delegação do líder empresarial. Substancialmente, segundo Meneghetti (2003), o empresário age por meio das múltiplas ações delegadas. Elas 
constituem o corpus orgânico relativo ao projeto pessoal da empresa.

Para o empreendedor, selecionar os atores diretos do projeto empresarial implica uma severa tomada de consciência, posto que a pessoa contratada para o interior do seu business estará ao seu lado ou poderá desorganizar completamente a estrutura gerenciada.

Essa pessoa deverá possuir, pelo menos, as seguintes capacidades mínimas, conforme explicita Meneghetti: capacidade técnica objetiva (conhecimento específico da área que pretende assumir ou organizar), capacidade de relação (estabelecer relações sadias com as pessoas com as quais trabalha) e a sua ambição de sucesso (desejo de evoluir e crescer pessoalmente dentro da organização). Nas empresas pesquisadas, constata-se que, entre a maioria dos entrevistados, há falhas nas suas capacidades técnicas objetivas, uma vez que desconhecem métodos adequados a serem aplicados no processo analisado em uma proporção superior a $90 \%$, mas compreendem os riscos a que estão submetidos sem tomarem atitudes para os solucionarem, apesar de a grande maioria $(80 \%)$ dos gestores estar na empresa há mais de dez anos, tempo suficiente para ajustar eventuais lacunas em sua formação profissional.

Pode haver diversas causas para essa situação atual, como, por exemplo, um processo de formação técnica ou acadêmica inadequado para a função que exercem (há a necessidade de conhecimentos mais amplos, como administração e direito, do que simplesmente conhecimentos técnicos em TI), que, inclusive, pode ser objeto de estudos e trabalhos futuros. As duas outras características, citadas por Meneghetti, não foram analisadas neste trabalho.

$\mathrm{O}$ cumprimento das exigências de um contrato, baseado no seu conceito jurídico, que é garantida pelo acompanhamento da execução e que para este trabalho é denominada de ciclo de vida de um contrato, foi estudada e descrita dentro de um modelo de processo, utilizando-se de uma metodologia própria de gestão de processos chamada BPM (Business Process Management). Ter um processo organizacional claro, que passa por todas as unidades funcionais participantes da corporação e que permite a sua própria melhoria contínua poderia trazer um cenário mais favorável ao resultado desta pesquisa, uma vez que restou comprovado um número expressivo de organizações com baixo nível de maturidade que não realizam um controle efetivo de contratos de TI.

O simples fato de uma organização passar a gerir com propriedade seus contratos de TI, utilizando gestão de processos com BPM, pode reduzir custos e exposição legal e, ainda, criar um fator de suporte à competitividade empresarial, além de poder expandir para outras áreas e atividades da empresa.

Portanto, o acompanhamento do ciclo de vida dos contratos de TI permite que os investimentos sejam melhor avaliados e direcionados de acordo com o plano estratégico da organização. O próprio ganho a ser obtido em relação ao baixo custo de investimento para implantação de um processo de gestão do ciclo de vida de um contrato justifica a busca de essas organizações melhorarem seus níveis de maturidade e ampliarem o estudo da abordagem proposta, trazendo ganhos à própria área de TI e, consequentemente, a toda organização.

BRONZATTI, Reges A.; BOER, Noemi. Avaliação do grau de maturidade dos processos de gestão de contratos de software e serviços de tecnologia da informação em empresas do Rio Grande do Sul. Revista Saber Humano, Recanto Maestro, n. 3, p. 145-158, 2013. 


\section{Referências}

ANGC. Associação Nacional de Gestores de Contratações. 2008. Disponível em: <www.angc.org.br>. Acesso em: 30 out. 2010.

ARNOLD, J. Administração de materiais: uma introdução. São Paulo: Atlas, 1999.

ARORA, S. Business Process Management: process is the enterprise. BPM-Strategy, 2005.

BATTAGLIA, D.; BORCHARDT, M. Análise do processo de recuperação de serviços a partir das reclamações dos clientes: estudo de caso em três organizações. Revista Produção Online 2010, Florianópolis (no prelo).

BALDAM, R. Gerenciamento de processos de negócio - BPM. 2. ed., São Paulo: Erica, 2010.

BULRTON, R. Business Process Management: Profiting from process. Indianapolis: Sams Publishing, 2001.

BRASIL. Lei 9609, de 19 de fevereiro de 1998. Dispõe sobre a proteção da propriedade intelectual de programa de computador, sua comercialização no País, e dá outras providências. Diário Oficial da República Federativa do Brasil, Brasília, DF, 20 fev. 1998. Número 36, Seção 1, p. 09-11.

CBOK. Guide to the Business Process Management Body of Knowledge - BPM CBOK. 2. ed. São Paulo: ABPMP, 2009.

COOPER, D.; SCHINDLER, P. Métodos de pesquisa em Administração. 7. ed., Porto Alegre: Bookman, 2003.

CRUZ, T. Sistemas, métodos e processos. São Paulo: Atlas, 2003.

FREITAS, W. Gestão de contratos: melhores práticas voltadas aos contratos empresariais. São Paulo: Atlas, 2009.

GOMES, O. Contratos. 26. ed., Rio de Janeiro: Forense, 2008.

GONÇALVES, J. E. L. As empresas são grandes coleções de processos. ERA: Revista de Administração de Empresas, São Paulo, v. 40, n. 1, p. 6-19, mar. 2000a.

JESTON, J.; NELIS, J. Business Process Management: practical Guidelines to succeful implementations. Oxford: Elsevier, 2006. p. 299 315.

KHAN, R. N. Business Process Management: a pratical guide. Tampa: Meghan-Kiffer Press, 2004.

LAURINDO, F.; ROTONDARO, R. Gestão integrada de processos e da tecnologia da informação. São Paulo: Atlas, 2008.

MALAMUT, G. Processos aplicados a sistemas integrados de gestão. In: SEMINÁRIO BRASILEIRO DE GESTÃO DE PROCESSOS, 1., 2005, Rio de Janeiro. Anais... Rio de Janeiro: SAGE-COPPE-UFRJ, 2005. p.1-120. Volume único.

MENEGHETTI, A. Economia, Política e Sociedade hoje. 4. ed. Recanto Maestro: Ontopsicologia Editrice, 2004.

MENEGHETTI, A. Psicologia da Organização. Sao Paulo: Foil, 2003.

ORRICO JUNIOR, Hugo. Pirataria de Software. São Paulo: MM Livros e Editora Distribuidora, 2004. 24

PAULK, M.C. et al. The capability maturity model for software. Version 1.1. ( $\mathrm{N}^{\circ} \mathrm{CMU} / \mathrm{SEI}-$ 93-TR-24) Software Engineering Institute. Disponível em: <http://www.sei.cmu.edu/cmm>. Acesso em: 26 out. 2010.

PEREIRA, Caio Mário da Silva. Instituições de Direito Civil. 13. ed., Rio de Janeiro: Forense, 2009.

SMITH, H.; FINGAR, P. Business Process Management: The Third Wave. Tampa: Meghan Kiffer, 2003.

SOFTEX. Associação para Promoção da Excelência do Software Brasileiro -

SOFTEX. MPS.BR - Guia de Aquisição:2009. Disponível em: <www.softex.br>. Acesso em: 28 mar. 2011.

PMI. Um guia do conhecimento em gerenciamento de projetos (PMBOK). 4. ed. Philadelphia: Project Management Institute, 2008.

PROBST, G. et al. Gestão do conhecimento: os elementos construtivos do sucesso. 2. ed., Porto Alegre: Bookman, 2002.

REIJERS, H. Implementing BPM systems: the role of process orientation.Business Process Management Journal, v. 12, n. 4, 2006.

BRONZATTI, Reges A.; BOER, Noemi. Avaliação do grau de maturidade dos processos de gestão de contratos de software e serviços de tecnologia da informação em empresas do Rio Grande do Sul. Revista Saber Humano, Recanto Maestro, n. 3, p. 145-158, 2013. 
ROSEMANN M. Potential pitfalls of process modeling. Business Process Management Journal, v. 12, n. 2, p. 249-254, 2006.

ROSEMANN M.; BRUIT, T. BPM Maturity. Application of a Holistic Model for Determining BPM Maturity. BPTrends, 2005. Disponível em: $<$ http://www.bptrends.com/> Acesso em: 13 out. 2010.

SCHEER, A. ARIS: business process framework. 2. ed., Berlin: Springer, 1998.

SAAD, ALFREDO C. Terceirização de serviços de tecnologia da informação. Rio de Janeiro: Brasport, 2006.

XAVIER, et al. Gerenciamento de aquisições em projetos. Rio de Janeiro: FGV, 2009.

YIN, R. K. Estudo de caso: planejamento e métodos. 3. ed. Porto Alegre: Bookman, 2005.

Autores:

Reges Antonio Bronzatti: Empresário do Setor de TI, Sócio e Diretor Administrativo do Grupo Processor, Advogado, Mestre em Ciência da Computação, Ex-Presidente da ASSESPRO-RS e do CETI ( Conselho das Entidades de TI do RS), Diretor da FEDERASUL, Professor MBA Unisinos em Gestão de TI, Professor da Disciplina de Direito aplicado a Informática, Perito Judicial em ações relacionadas à Tecnologia da Informação. Pós-Graduado em MBA O Empreendedor e a Cultura Humanista da AMF.

Noemi Boer: Bióloga, Doutora em Educação Científica e Tecnológica (UFSC), professora universitária (UNIFRA), professora convidada dos cursos de Pós-Graduação Lato Sensu MBA Faculdade Antonio Meneghetti.

Submetido em: $11 / 05 / 2013$

Aceito em: 07/08/2013

BRONZATTI, Reges A.; BOER, Noemi. Avaliação do grau de maturidade dos processos de gestão de contratos de software e serviços de tecnologia da informação em empresas do Rio Grande do Sul. Revista Saber Humano, Recanto Maestro, n. 3, p. 145-158, 2013. 